\title{
Kim Kŭnbae. Han'guk kŭndae kwahak kisul illŏk ŭi ch'ulhyŏn [The Emergence of Modern Korean Scientific and Technological Manpower]
}

\author{
Seoul: Munhak kwa chisŏngsa, 2005
}

\author{
Min Suh Son
}

Received: 12 September 2007 / Accepted: 12 September 2007 /

Published online: 18 April 2008

(C) National Science Council, Taiwan 2008

For years now, historians of science and technology in Korea have shied away from the late nineteenth to early twentieth century largely to avoid dealing with the implications of the Japanese colonial period as it relates to Korea's modernization and modernity. This is in no small part a consequence of the shortage of primary sources on this topic from the Taehan Empire period (1897-1910) and the predominance of Japanese sources for the colonial era (1910-1945), which would lead anyone to the cursory conclusion that modern science and technology emerged in Korea through the singular efforts of the Japanese.

It is no wonder then that Kim Kŭnbae undertook the momentous task of documenting this period in a book that covers what is essentially a gaping hole in our knowledge of science and technology in Korea between the years 1897 and 1945. Admittedly discouraged by the lack of sources and affected by personal feelings towards the colonial past, Kim expresses his reluctance to examine this period of which he writes, "The topic of my doctoral dissertation initially dealt with Korean science in the post-liberation period. This was because it seemed that the kaehwa (Enlightenment) period was heavily steeped in tradition while the colonial period had no real emotional pull for me. However, I soon came up against two problems, namely, the complete lack of sources and the poverty of understanding on the period immediately preceding it" (7).

Over the course of four chapters, this book addresses the introduction; expansion; and, ultimately, deterioration of scientific and technological training begun during the Taehan Empire to Korea's liberation from Japanese occupation in 1945. This ambitious project focuses primarily on positioning the Korean people as central agents in the cultivation and development of manpower at this time, answering basic yet essential questions regarding how scientific knowledge was acquired, by whom it was acquired, and how things changed under the colonial regime.

\footnotetext{
M. S. Son $(\bowtie)$

History of Science and Technology, Johns Hopkins University, Baltimore, MD, USA

e-mail: minsuh@jhu.edu
} 
The first chapter examines the rise of science and technological studies between 1897 and 1910 in a search for continuity between preoccupation Korea and the colonial period. Kim argues that a significant amount of local development in scientific and technological studies existed even before the Japanese arrived on the scene. Kim accomplishes what he sets out to do, presenting an abundance of data - numbers on student enrollments, general curricular information, and even tracing specific career paths of individuals - a heady task of original research that was clearly the result of painstakingly combing through dense primary-source materials.

Although the story that emerges from these statistics is one of shifting status structures as people from lower- and middle-status groups filled these schools and traveled overseas to study, unfortunately, we receive limited analysis to this effect. It seems that if Kim had used these data towards a broader degree of analysis to see how it related to other sociopolitical changes beyond the specific purview of scientific and technological training - especially when linked to other secondary work that has been conducted on topics such as political participation, social activism, lifestyle, culture, and thought - then the resulting narrative could be an important one in understanding the attitudes of common people towards modernization and modernity at the everyday level in this underexamined era.

The next three chapters span the entire colonial period. The second chapter examines the time during which the Japanese were stabilizing their rule in Korea. During this stage, Koreans were enrolled mostly in inferior industrial schools whose instruction was not widely acknowledged while Japanese students dominated the enrollment of officially established industrial schools - a situation that reflected the institutionalized ceiling placed on Korean education. The third chapter, which covers 1919 to 1935, argues that, despite the increasingly oppressive policies and activities of the Japanese Government-General, the study of science and technology among Koreans continued to rise exponentially through their increased enrollment in Japanese and private industrial schools. Kim interprets this as a product of Koreans' desire to improve their material conditions rather than as a result of any particularly generous policy by the Japanese, although he reminds us that these conditions were determined strictly within the colonial context. The fourth and final chapter brings us to the end of the colonial period and reveals a shift in popular interest in education that demonstrates greater organization and collectivity amongst Koreans during a time of heightened oppression and mobilization for war by the Japanese.

The portrait that is painted is one wherein the Korean colonial subject is both institutionally disenfranchised and continuously working within this system to improve their conditions. Kim's interpretation, however, implicitly feeds into a larger nationalistic narrative of resistance where manipulating the system is seen as a way of asserting the Korean ethnic nation and identity. As Kim admits, the relationship between the colonial subject and the colonizer was so entangled that it was often difficult to properly identify Koreans or Japanese statistically. If this were true, it would suggest that the argument for resistance (or complicity) could be more complicated and nuanced than presented here. Although he clearly admitted from the outset that he was writing from a nationalistic agenda in a search for the autonomous roots of scientific and technological studies, and though he paints a good case for the fact that significant strides were made in the Taehan empire period towards scientific and technological development independent of Japan, his agenda is too overarching 型 Springer 
at the expense of a more neutral interpretation. Like many historians of this period, he avoids addressing issues of collaboration implicit in situations where Koreans are assimilated into colonial institutions not because he does not agree with the binary labels of resistance vs collaboration but it seems rather because he buys into it. As a result, he continues to assert authentically Korean educational institutions, organizations, and collectives that he portrays as discernible from the colonial machine.

What is also missing is a narrative of life in precolonial and colonial Korea and what these changes meant in everyday terms, especially terms of the formation of a Korean identity within a colonial empire. It leaves one wondering what happened to the worldview and self-perception of students returning home from their government scholarships abroad in Japan as colonial subjects or Koreans. What did this mean more generally in terms of the function of science and technology within Korean society?

Overall, however, this study is nothing if not meticulous and helps make sense of a poorly understood era. Kim Kŭnbae has exhaustively researched and documented this book, providing us with a richness of data that will prove to be an invaluable tool for other historians and will be a great foundation for further scholarship on this topic. Not only has he managed to fill the gap, he has flooded the gap with so much material that it may take another book at the very least to properly flesh out the significance of the data offered here. He claims to have started out apprehensive of the lack of sources on this topic, yet he provides us with a wealth of information that, even by itself, is an important contribution to the field. 